\title{
Extraneural CGRP Upregulates TGF- $\beta 1$ through RAMP1 Signaling during Mechanical Stretch in Kidney Proximal Tubule Epithelial Cells
}

\author{
Daeun Moon $\mathbb{D}^{1}$, Babu J. Padanilam $\mathbb{D}^{2}$, Hee-Seong Jang $\mathbb{D}^{2}$, Jinu Kim $\mathbb{D}^{1,3}$ \\ ${ }^{1}$ Interdisciplinary Graduate Program in Advanced Convergence Technology \& Science, Jeju National University \\ ${ }^{2}$ Department of Cellular and Integrative Physiology, University of Nebraska Medical Center \\ ${ }^{3}$ Department of Anatomy, Jeju National University School of Medicine
}

\begin{abstract}
Calcitonin gene-related peptide (CGRP) derived from sensory neurons contributes to the development of renal tubulointerstitial fibrosis during ureteral obstruction through upregulation of profibrotic factors. However, the mechanism by which CGRP upregulates the profibrotic factors in the ureteral obstructive setting in the kidney tubule epithelial cells is not defined. In the human kidney proximal tubule epithelial cell line, HK-2, treatment with $1 \mathrm{nM}$ CGRP significantly enhanced transforming growth factor- $\beta 1$ (TGF- $\beta 1$ ) production, its release, and protein kinase $\mathrm{C}$ (PKC) activity. Furthermore, mechanical stretch for 6 and 24 hours significantly increased expressions of receptor activity modifying protein 1 (RAMP1) mRNA and protein among CGRP receptor components in HK-2 cells. In addition, a combination treatment with CGRP and mechanical stretch synergistically increased TGF- $\beta 1$ upregulation and PKC activation. However, RAMP1 deficiency, induced by RAMP1 double nickase plasmid transfection, abolished CGRP-induced TGF- $\beta 1$ upregulation and PKC activation in HK-2 cells with or without mechanical stretch. Finally, pharmacological inhibition of PKC markedly reduced TGF- $\beta 1$ production and release after treatment of HK- 2 cells with CGRP. Taken together, these data suggest that extraneural CGRP upregulates TGF- $\beta 1$ through RAMP1-PKC axis during mechanical stretch in kidney proximal tubule epithelial cells.
\end{abstract}

Keywords : Fibrosis, Calcitonin gene-related peptide, RAMP1, TGF- $\beta$, Protein kinase C

\section{INTRODUCTION}

Fibrosis is responsible for sustained or repetitive progressive tissue injury in various organs. During progression of acute kidney injury to chronic kidney disease (CKD), a persistent injury and/or an incomplete restoration in kidney

The author(s) agree to abide by the good publication practice guideline for medical journals.

The author(s) declare that there are no conflicts of interest.

Received: December 4, 2020; Revised: December 14, 2020;

Accepted: December 16, 2020

Correspondence to: Jinu Kim (Department of Anatomy, Jeju National University School of Medicine 102 Jejudaehak-ro, Jeju 63243, Republic of Korea)

E-mail: jinu.kim@jejunu.ac.kr tubular epithelial cells occur mainly through fibroblast proliferation and extracellular matrix accumulation [1]. The injured kidney tubular epithelial cells have an active role in the development and progression of kidney fibrosis through upregulation of profibrogenic factors [2]. Among various profibrogenic factors, transforming growth factor- $\beta$ (TGF- $\beta$ ) is a well-established inducer of kidney fibrosis and plays a key role in the pathogenesis of CKD [3-5]. Upregulation of TGF- $\beta$ in both tubular and interstitial cells is a universal finding in virtually every type of kidney fibrosis in human and rodent in vivo models [6,7]. In in vitro systems, treatment with TGF- $\beta$ stimulates interstitial fibroblast to undergo myofibroblast activation to produce extracellular 
matrix proteins including collagen and fibronectin [8]. TGF- $\beta$ signaling pathway in kidney tissue also integrates effects of other profibrogenic factors including connective tissue growth factor [9]. Inhibition of TGF- $\beta$ by multiple strategies suppresses kidney fibrogenesis, resulting in the prevention of progressive kidney dysfunction [5]. Previously, our in vivo data have indicated that kidney denervation prevents the development of renal tubulointerstitial fibrosis induced by a unilateral ureteral obstruction (UUO), but the local administration of calcitonin gene-related peptide (CGRP), which is a neuropathic peptide mostly secreted from sensory neurons among vertebrates [10], into denervated and ureteral-obstructed kidneys revives the fibrotic lesions observed in innervated and ureteral-obstructed kidneys [11]. Intriguingly, the CGRP neuropeptide is upregulated in kidney proximal tubule epithelial cells during UUO [11]. Although our previous study has demonstrated that exogenous CGRP upregulates TGF- $\beta$ in kidney proximal tubule epithelial cells [12], it is still unclear whether and how CGRP contributes to the upregulation of intracellular TGF- $\beta$ under the ureteral obstructive condition. In order to define the mechanism of an in vitro stress model, the mechanical stretch was used to mimic conditions in UUO. The mechanical stretch in kidney tubular epithelial cells is the sole model that mimics the pathogenic effects of tubular distension induced by UUO and can provide a mechanism to upregulate fibrosis-related genes [13].

CGRP receptor is a heterodimer consisting of receptor activity modifying protein 1 (RAMP1) and calcitonin receptor-like receptor (CRLR) [14]. RAMP1 is required for the translocation of CRLR to form a functional CGRP receptor, suggesting that RAMP1 is essential for CGRP receptor signaling [10]. Expression of the CGRP receptor is detected in the nervous system including trigeminal ganglia, brainstem, cerebellum, and cerebral vasculature [15], as well as in kidney tubule epithelial cells $[12,16]$. The intracellular signaling pathway of CGRP receptor can be involved in protein kinase $\mathrm{C}(\mathrm{PKC})$ activation and translocation to the membrane fraction of cells $[17,18]$. The PKC family of serine/ threonine kinases is implicated in various fibrotic diseases and responses [19-21]. However, unlike an integral role of CGRP and its receptor signaling in the pathophysiology of migraine is established [10], the role of CGRP receptor in extra-neural sites is unclear. Thus, detailed knowledge of RAMP1 downstream pathway and its regulation can be essential to understanding the physiological role of CGRP in kidney fibrosis. Here, we sought to determine whether RAMP1 deficiency reduces CGRP-induced TGF- $\beta$ upregulation during mechanical stretch in kidney proximal tubule epithelial cells.

\section{MATERIALS AND METHODS}

\section{Cell culture and mechanical stretch}

The HK-2 human kidney proximal tubule epithelial cells (American Type Culture Collection, Rockville, MD, USA) were grown in Roswell Park Memorial Institute (RPMI) 1640 (Welgene, Daegu, Korea) supplemented with $10 \%$ fetal bovine serum (FBS, Welgene) at $37^{\circ} \mathrm{C}$ with $5 \% \mathrm{CO}_{2}$, as previously described [22-24]. When the cells grew until 70\% confluence on Bioflex 6-well culture plates with flexible sheets coated with type I collagen (Flexcell International, McKeesport, PA, USA), mechanical stretch was carried out in serum-free medium using a computer-controlled FX5000 tension system (Flexcell International) with cycles of 5 second-stretch and 5 second-relaxation at a strain of $15 \%$, as previously described [25]. The stretch was applied to the cells for 0,6 or 24 hours in $\mathrm{CO}_{2}$ incubator at $37^{\circ} \mathrm{C}$ with $5 \%$ $\mathrm{CO}_{2}$. Phosphate-buffered saline (vehicle), CGRP (1 nM, R\&D Systems, Minneapolis, MN, USA) or chelerythrine chloride (1 to $100 \mu \mathrm{M}, \mathrm{R} \& \mathrm{D}$ Systems), a broad range PKC inhibitor, was added at the onset of stretch.

\section{RAMP1 deficient cells}

Cells were transfected with either RAMP1 double nickase plasmid (catalog no. sc-401396-NIC; Santa Cruz Biotechnology, Santa Cruz, CA, USA) for inducing RAMP1 gene knockout $(\mathrm{KO})$ or control double nickase plasmid (Santa Cruz Biotechnology) for wild-type (WT) in $300 \mu \mathrm{L}$ of plasmid transfection medium (Santa Cruz Biotechnology) with $15 \mu \mathrm{L}$ of UltraCruz transfection reagent (Santa Cruz Biotechnology) for 48 hours. After that, the transfected cells were isolated using $10 \mu \mathrm{g} / \mathrm{mL}$ of puromycin (Sigma, St. Louis, MO, USA) for 4 days, as previously described [26,27].

\section{Western blot}

Electrophoresis of protein extracts obtained from cell lysates using Tris-glycine buffer systems and subsequent blotting were performed as previously described [28-30]. 
The membranes were incubated with antibodies against RAMP1 (1 :2,500 dilution; catalog no. 10327-1-AP; Proteintech, Chicago, IL, USA), CRLR ( $1: 2,500$ dilution; cata$\log$ no. sc-18007; Santa Cruz Biotechnology), green fluorescent protein (GFP, Proteintech), and $\beta$-actin (Sigma). After that, peroxidase-conjugated secondary antibodies (Vector Laboratories, Burlingame, CA, USA) were incubated. To detect the proteins, a chemiluminescence reagent (PerkinElmer, Boston, MA, USA) was used. Antibodies for GFP and $\beta$-actin were used as a transfecting control and loading control, respectively. The bands were quantified using AzureSpot analysis software (Azure Biosystems, Dublin, CA, USA).

\section{Real-time reverse transcription-polymerase chain reaction (RT-PCR)}

Intracellular RNA was extracted using TRIzol reagent (ThermoFisher Scientific, Pittsburgh, PA, USA) and cleaned with RNeasy mini kit (Qiagen, Hilden, Germany). After cDNA synthesis using iScript cDNA synthesis kit (Bio-Rad, Hercules, CA, USA), mRNA levels were assessed using a SYBR Green master mix on an ABI Prism 7500 sequence detection system (Applied Biosystems, Foster City, CA, USA) as previously described $[31,32]$. The following primers were used: human RAMP1 (forward: ACCTCTTCATGAC CACTGCC; reverse: AAGAACCTGTCCACCTCTGG) and human CRLR (forward: ATGGAGAAAAAGTGTAC CCT; reverse: CATGTTCTGTTGCTTGCTGG). Cycle conditions were as follows: after an initial hold of 2 minutes at $50^{\circ} \mathrm{C}$ and 10 minutes at $95^{\circ} \mathrm{C}$, the samples were cycled 40 times at $95^{\circ} \mathrm{C}$ for 15 seconds and $60^{\circ} \mathrm{C}$ for 60 seconds. The levels were normalized to human peptidylprolyl isomerase A (forward: GGCAAATGCTGGACCCAACACA; reverse: TGCTGGTCTTGCCATTCCTGGA) signal amplified in a separate reaction.

\section{Enzyme-linked immunosorbent assay (ELISA)}

Levels of TGF- $\beta 1$ production and release were measured in $30 \mu \mathrm{g}$ protein in whole-cell lysates and $100 \mu \mathrm{L}$ of culture media using TGF-beta1 Quantikine ELISA kit (R\&D Systems) as previously described $[25,33]$. PKC activity was measured in $30 \mu \mathrm{g}$ protein in whole-cell lysates using PKC kinase activity kit (Enzo Life Sciences, Farmingdale, NY, USA) as previously described [12]. All ELISA experiments were performed according to the respective manufacturer's protocols.

\section{Statistical analysis}

All data are expressed as mean \pm standard error of the mean (SEM). Analysis of variance was used to compare data among groups using Systat SigmaPlot (Systat Software Inc., San Jose, CA, USA). Differences between the two groups were assessed using two-tailed unpaired Student's $t$-tests. $P$ values $<0.05$ were considered statistically significant.

\section{RESULTS}

\section{Mechanical stretch increases RAMP1 mRNA and protein expression in kidney proximal tubule epithelial cells}

To study the role of CGRP receptor during high intrarenal pressure, we employed an in vitro system model of cyclic mechanical stretch in human kidney proximal tubule epithelial, HK-2, cells and then assessed protein and mRNA expression of CGRP receptor components. After 6 and 24 hours of mechanical stretch, expression of RAMP1 protein at approximately $14 \mathrm{kDa}$ was significantly increased, whereas expression of CRLR protein at approximately $60 \mathrm{kDa}$ was not altered (Fig. 1A and B). Consistent with the result of protein expression, mechanical stretch also upregulated RAMP mRNA, but not altered the level of CRLR mRNA (Fig. 1C). These results indicate that mechanical stretch selectively upregulates RAMP1 among CGRP receptor components in kidney proximal tubule epithelial cells.

\section{Exogenous CGRP enhances TGF- $\beta 1$ production and release during mechanical stretch in kidney proximal tubule epithelial cells}

Other studies have shown that mechanical stretch increases TGF- $\beta 1$ production and release in mesangial cells [34] and tendon cells [35], respectively. In the present study, we tested whether the production and release of TGF- $\beta 1$ protein were also increased by mechanical stretch in HK-2 . After 6 and 24 hours of mechanical stretch, the HK-2 cells showed significant increases in the production and release of TGF- $\beta 1$ (Fig. $2 \mathrm{~A}$ and B). Since exogenous CGRP also affects TGF- $\beta 1$ signaling in kidney proximal tubule epithelial cells [12], we next treated HK-2 cells with CGRP 

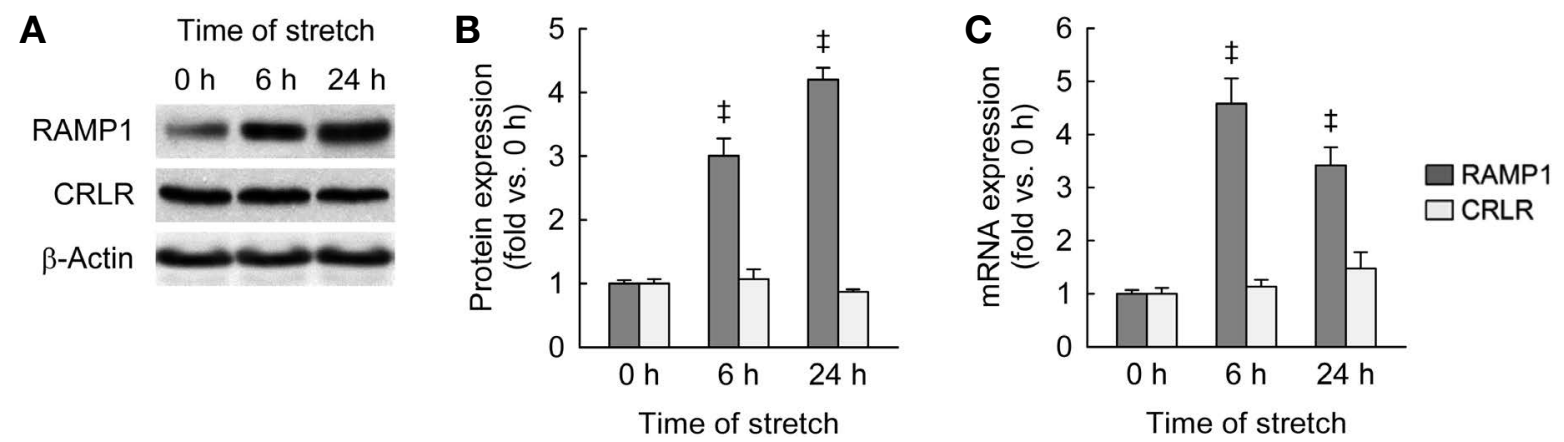

Fig. 1. Mechanical stretch upregulates RAMP1 in kidney proximal tubule epithelial cells. Human kidney proximal tubule epithelial (HK-2) cells were stretched for 0,6 or 24 hours ( $n=4$ experiments per condition). (A) RAMP1 and CRLR protein expression were measured using western blot analysis. The antibody for $\beta$-actin was used as a loading control. (B) The intensities of protein bands were quantified using the AzureSpot software. (C) RAMP1 and CRLR mRNA expression were measured using real-time quantitative RT-PCR. Data are shown as mean \pm SEM. ${ }^{\ddagger} P<0.05$ versus 0 hour.
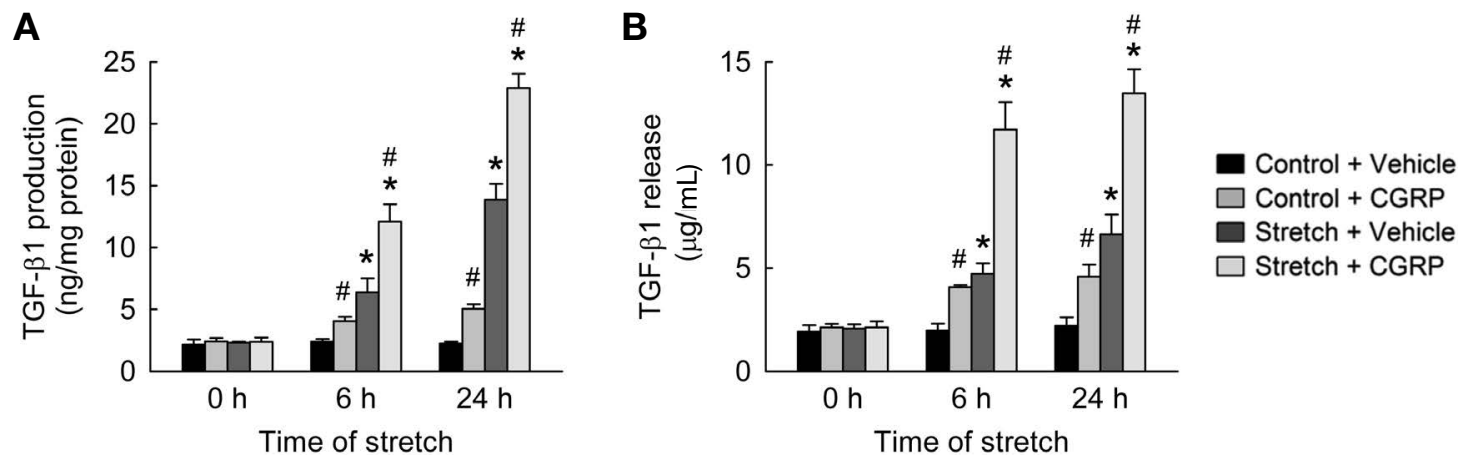

Fig. 2. Mechanical stretch and CGRP enhance TGF- $\beta 1$ production and release in kidney proximal tubule epithelial cells. HK-2 cells were stretched for 0,6 or 24 hours with treatment with vehicle or $1 \mathrm{nM} \mathrm{CGRP(} n=4$ experiments per condition). (A) Intracellular level of TGF- $\beta 1$ was measured using ELISA. (B) Released level of TGF- $\beta 1$ was measured using ELISA. Data are shown as mean \pm SEM. $* P<0.05$ versus control+vehicle, ${ }^{\$} P<0.05$ versus control + CGRP, ${ }^{\#} P<0.05$ versus stretch + vehicle.

during mechanical stretch and then measured TGF- $\beta 1$ production and release. Consistent with previously reported data [12], treatment with CGRP significantly increased the production and release of TGF- $\beta 1$ in HK- 2 cells without mechanical stretch (Fig. 2A and B). Furthermore, treatment with CGRP in HK-2 cells with 6 and 24 hours of mechanical stretch remarkably increased the TGF- $\beta 1$ production $(P=0.002$ versus stretch + vehicle and $P<0.001$ versus control + CGRP $)$ and release $(P=0.003$ versus stretch + vehicle and $P<0.001$ versus control + CGRP) (Fig. 2A and $B)$. However, treatmemt with CGRP and/or mechanical stretch did not induce a mesenchymal cell-like phenotype in HK-2 cells demonstrated with a light microscope (data not shown), consistent with previous data $[12,25]$. These results indicate that a combination of exogenous CGRP and mechanical stretch induces synergistic upregulation of
TGF- $\beta 1$ in kidney proximal tubule epithelial cells.

\section{RAMP1 deficiency abolishes the synergistic effect of CGRP for TGF- $\beta 1$ production and release after mechanical stretch in kidney proximal tubule epithelial cells}

The synergistic effect of CGRP and mechanical stretch in the production and release of TGF- $\beta 1$ may be through the RAMP1 upregulation in kidney proximal tubule epithelial cells. In order to confirm this, RAMP1-deficient HK-2 cells were developed using transfection with double nickase plasmid encoding RAMP1 and treatment with a puromycin antibiotic (Fig. 3A). The effect of RAMP1-deficiency in TGF- $\beta 1$ production and release after treatment with CGRP was investigated. The RAMP1-deficient cells showed suppression of production and release of TGF- $\beta 1$ induced by 
A

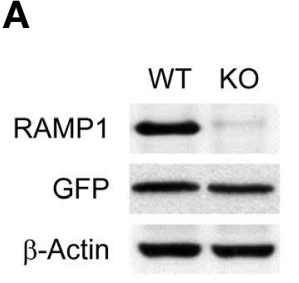

B

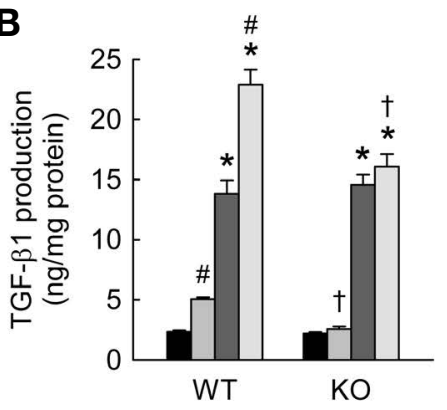

Twenty-four hours of stretch and treatment

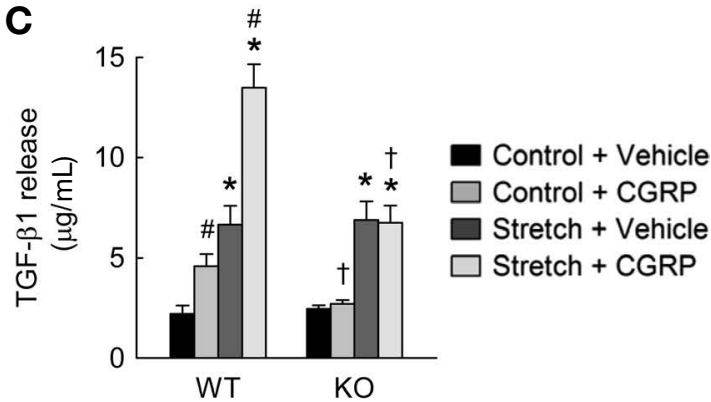

Twenty-four hours of stretch and treatment

Fig. 3. RAMP1 deficiency abolishes CGRP-induced TGF- $\beta 1$ upregulation in kidney proximal tubule epithelial cells. HK-2 cells were transfected with either control plasmid (wild-type, WT) or RAMP1 double nickase plasmid (knockout, KO) and stretched for 24 hours immediately after treatment with vehicle or $1 \mathrm{nM}$ CGRP ( $n=4$ experiments per condition). (A) Expression of RAMP1 protein was confirmed using western blot analysis. Antibodies for $\beta$-actin and GFP were used as a loading control and a transfection control, respectively. (B) Intracellular level of TGF- $\beta 1$ measured using ELISA. (C) Released level of TGF- $\beta 1$ measured using ELISA. Data are shown as mean \pm SEM. $* P<0.05$ versus control + vehicle, ${ }^{\$} P<0.05$ versus control + CGRP, ${ }^{\#} P<0.05$ versus stretch + vehicle, ${ }^{\dagger} P<0.05$ versus respective WT.
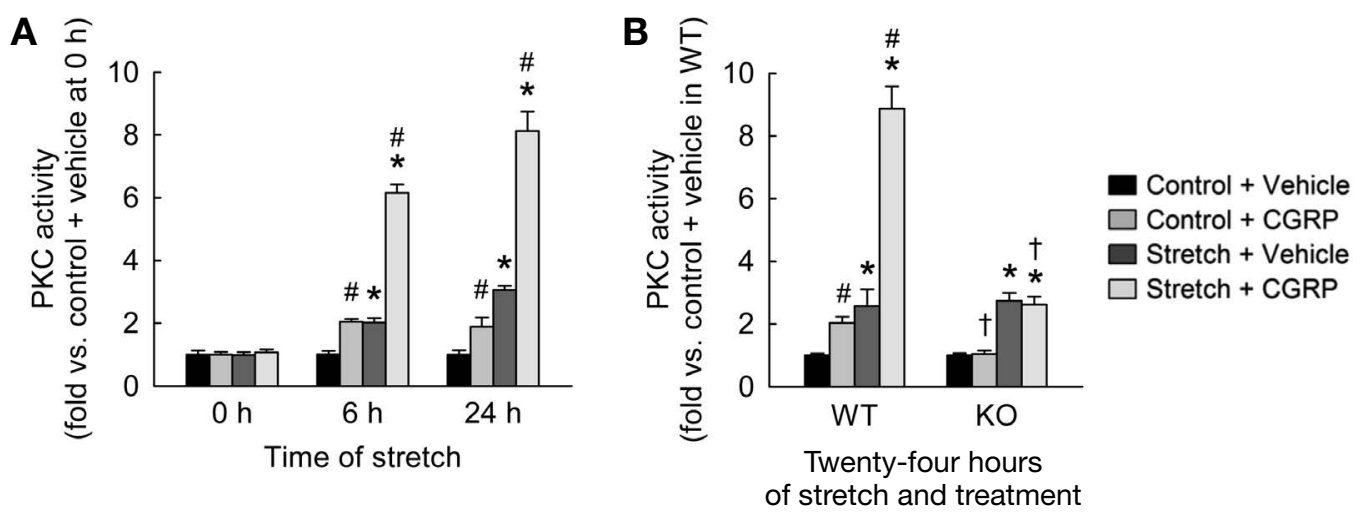

Fig. 4. RAMP1 deficiency suppresses CGRP-induced PKC activation in kidney proximal tubule epithelial cells. (A) HK-2 cells were stretched for 0,6 or 24 hours immediately after treatment with vehicle or $1 \mathrm{nM}$ CGRP. PKC activity was evaluated using a PKC kinase activity kit ( $n=4$ experiments per condition). (B) RAMP1-KO and WT HK-2 cells were stretched for 24 hours immediately after treatment with vehicle or $1 \mathrm{nM} \mathrm{CGRP} \mathrm{(} n=4$ experiments per condition). PKC activity was measured using the PKC kinase activity kit. Data are shown as mean \pm SEM. ${ }^{*} P<0.05$ versus control + vehicle, ${ }^{\$} P<0.05$ versus control $+\mathrm{CGRP},{ }^{\sharp} P<0.05$ versus stretch + vehicle; ${ }^{\dagger} P<0.01$ versus respective WT.

exogenous CGRP(Fig. 3B and C). However, the RAMP1 deficiency did not significantly reduce the production and release of TGF- $\beta 1$ induced by mechanical stretch (Fig. 3B and $\mathrm{C}$ ). These results indicate that CGRP increases TGF- $\beta 1$ production and release through its receptor in kidney proximal tubule epithelial cells, but the mechanical stretchinduced TGF- $\beta 1$ upregulation is independent of RAMP1. Thus, the additive effect of these independent pathways may explain the synergistic effect observed in TGF- $\beta 1$ production and release during mechanical stretch combined with treatment with CGRP.

\section{The synergistic effect of CGRP and mechanical stretch in TGF- $\beta 1$ production and release is mediated through PKC activation in kidney proximal tubule epithelial cells}

PKC is not only activated rapidly in stretched mesangial cells [36], but also implicated in the intracellular signaling pathway of RAMP1 in bronchial epithelial cells [18]. To determine whether PKC is activated after mechanical stretch and/or treatment with CGRP in kidney proximal tubule epithelial cells, we measured PKC activity in HK-2 cells using ELISA assay. After 6 and 24 hours of either 

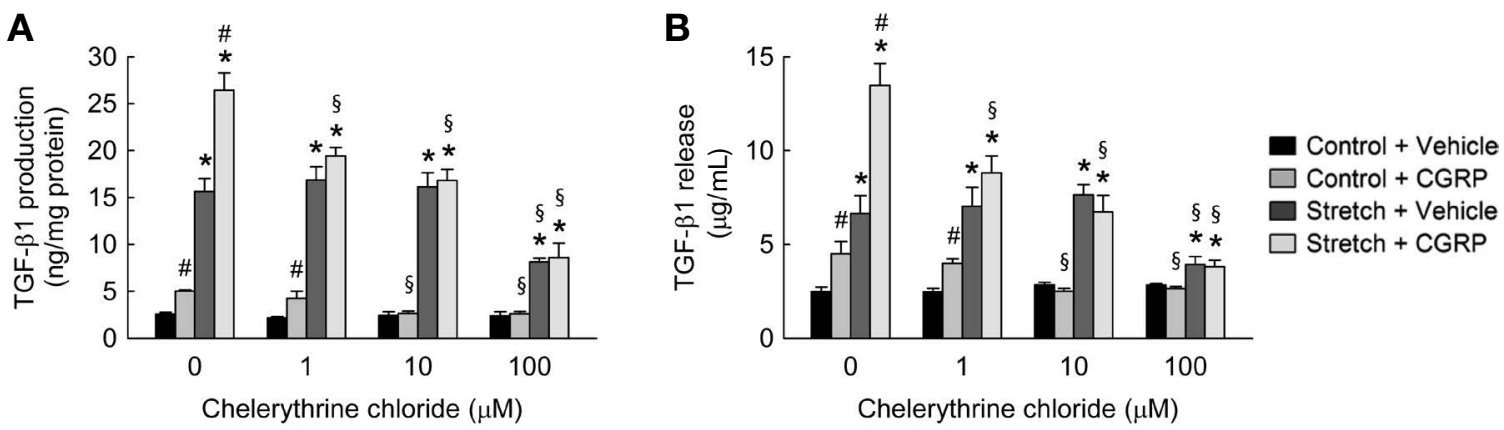

Fig. 5. PKC inhibition attenuates TGF- $\beta 1$ upregulation induced by CGRP and mechanical stretch in kidney proximal tubule epithelial cells. HK-2 cells were stretched for 24 hours immediately after treatment with vehicle or CGRP. The cells were also treated with $0,1,10$ or 100 $\mu \mathrm{M}$ chelerythrine chloride, a broad range PKC inhibitor, at the onset of stretch ( $n=4$ experiments per condition). (A) Intracellular level of TGF- $\beta 1$ was measured using ELISA. (B) Released level of TGF- $\beta 1$ was measured using ELISA. Data are shown as mean \pm SEM. $* P<0.05$ versus control + vehicle, ${ }^{\$} P<0.05$ versus control + CGRP, ${ }^{\#} P<0.05$ versus stretch+vehicle, ${ }^{\S} P<0.05$ versus respective $0 \mu \mathrm{M}$.

mechanical stretch or treatment with CGRP, the HK-2 cells showed a significant increase in PKC activity and a combination treatment with CGRP and mechanical stretchinduced an additive effect and exacerbated PKC activity (Fig. 4A). When PKC activity was examined in RAMP-deficient HK-2 cells, the excessive increment of PKC activity after treatment with CGRP was abolished by the RAMP deficiency, whereas the increase in PKC activity after mechanical stretch was not affected by the RAMP deficiency (Fig. 4B). Intriguingly, pharmacological inhibition of PKC with a PKC inhibitor dose-dependently attenuated production and release of TGF- $\beta 1$ after treatment with CGRP and/or mechanical stretch in HK-2 cells (Fig. 5A and B). These results indicate that exogenous CGRP-induced TGF- $\beta 1$ upregulation as well as mechanical stretch-induced TGF- $\beta 1$ upregulation employ PKC activation, albeit via alternate pathways. The mechanism by which mechanical stress induces PKC activation remains to be investigated.

\section{DISCUSSION}

Fibrosis is necessary to restore tissue architecture in organ regeneration, but excessive fibrosis leads to various types of chronic diseases. The pathophysiological events during renal tubulointerstitial fibrosis are complex and include several independent and overlapping cell signaling pathways. The experimental UUO is a representative model used to study renal tubulointerstitial fibrosis, which is characterized by interstitial expansion, tubular epithelial cell death, tubular dilation, loss of proximal tubular mass, and leukocyte influx. These alterations are a consequence of molecular processes such as mechanical stretch, oxidative stress and inflammation; which altogether lead to the development of renal tubulointerstitial fibrosis. Increased renal pelvic pressure is observed in early UUO, although it begins to fall during late UUO because of dilated renal pelvis, slow renal blood flow, and lower glomerular filtration rate $[13,37]$. These alterations are related to mechanical stretch of kidney tubule epithelial cells in vitro, indicating that mechanical stretch in kidney tubular epithelial cells is the most suitable model that imitates the pathogenic effects of tubular distention by urine in ureteral-obstructed kidneys. However, the molecular signaling pathways that elicit renal tubulointerstitial fibrosis in kidney tubular epithelial cells during mechanical stretch have not been defined.

Sensory nerve-secreted CGRP does not only function as a key player in the immune response and the regulation of peripheral inflammation [38], but also contributes to the development of renal tubulointerstitial fibrosis. In our previous work [11], it has been presented that kidney denervation dramatically suppressed the upregulation of profibrotic growth factors, including TGF1- $\beta 1$, after UUO and abolished the induction of renal tubulointerstitial fibrosis. Meanwhile, local infusion of CGRP into the cortex of denervated kidneys mimicked the fibrotic injury induced by UUO. Consistent with the previous finding in vivo, our data in kidney proximal tubule epithelial cells demonstrate that exogenous CGRP increases TGF- $\beta 1$ production and its release. Intriguingly, a combination of exogenous CGRP and mechanical stretch leads to added upregulation of TGF- $\beta 1$ in kidney proximal tubule epithelial cells. We demonstrate that 
RAMP1 among CGRP receptor components is selectively upregulated by mechanical stretch in kidney proximal tubule epithelial cells. This may cause the synergistic effect of CGRP for TGF- $\beta 1$ production and release after mechanical stretch in kidney proximal tubule epithelial cells.

TGF- $\beta$ signaling has been known as a key stimulator in renal tubulointerstitial fibrosis because of its ability to stimulate the synthesis and deposition of extracellular matrix molecules including fibronectin and collagen [4]. The level of TGF- $\beta$ protein expression is increased by PKC activation, especially PKC- $\beta 1$ among PKC subtypes, in mesangial cells [39]. Because the PKC family exerts its actions by phosphorylating a variety of cellular targets, it can be implicated in various fibrotic diseases and responses. In diabetes-induced renal fibrosis, it has been reported that PKC- $\beta$ deficiency attenuates the expression of profibrotic growth genes including TGF- $\beta$ [40]. PKC is also activated by CGRP-RAMP1 axis in bronchial epithelial cells, which is phosphorylated after treatment with CGRP [18]. Our present data have also shown that exogenous CGRP induces PKC activation through RAMP1 during mechanical stretch in kidney proximal tubule epithelial cells, but pharmacological inhibition of PKC reduces TGF- $\beta 1$ expression and release. These data suggest that exogenous CGRP-induced TGF- $\beta 1$ upregulation is mediated by $\mathrm{PKC}$ activation during mechanical stretch in kidney tubule epithelial cells.

In summary, the results of this study have demonstrated that treatment of kidney proximal tubule epithelial cells treated with CGRP or mechanical stretch upregulates RAMP1 expression. CGRP induces TGF- $\beta 1$ production and release through RAMP1-PKC axis, while mechanical stretch may induces TGF- $\beta 1$ production and release through alternative pathway. Identification of the mechanism of PKC activation during mechanical stretch may help in designing strategies to intervene in the pathway and developing combination treatment strategies to alleviate renal tubulointerstitial fibrosis in chronic kidney disease.

\section{CONFLICTS OF INTEREST}

The authors have no conflict of interest to declare.

\section{REFERENCES}

1. Boor P, Ostendorf T, Floege J. Renal fibrosis: novel insights into mechanisms and therapeutic targets. Nat Rev Nephrol. 2010;6:643-56.

2. Liu Y. Renal fibrosis: new insights into the pathogenesis and therapeutics. Kidney Int. 2006;69:213-7.

3. Bottinger EP, Bitzer M. TGF-beta signaling in renal disease. J Am Soc Nephrol. 2002;13:2600-10.

4. Border WA, Noble NA. TGF-beta in kidney fibrosis: a target for gene therapy. Kidney Int. 1997;51:1388-96.

5. Yanagita M. Inhibitors/antagonists of TGF-beta system in kidney fibrosis. Nephrol Dial Transplant. 2012;27:3686-91.

6. Yamamoto T, Nakamura T, Noble NA, Ruoslahti E, Border WA. Expression of transforming growth factor beta is elevated in human and experimental diabetic nephropathy. Proc Natl Acad Sci USA. 1993;90:1814-8.

7. Kaneto H, Morrissey J, Klahr S. Increased expression of TGF-beta 1 mRNA in the obstructed kidney of rats with unilateral ureteral ligation. Kidney Int. 1993;44:313-21.

8. Strutz F, Zeisberg M, Renziehausen A, Raschke B, Becker $\mathrm{V}$, van Kooten $\mathrm{C}$, et al. TGF-beta 1 induces proliferation in human renal fibroblasts via induction of basic fibroblast growth factor(FGF-2). Kidney Int. 2001;59:579-92.

9. Yokoi H, Sugawara A, Mukoyama M, Mori K, Makino H, Suganami T, et al. Role of connective tissue growth factor in profibrotic action of transforming growth factor-beta: a potential target for preventing renal fibrosis. Am J Kidney Dis. 2001; 38:S134-8.

10. Russell FA, King R, Smillie SJ, Kodji X, Brain SD. Calcitonin gene-related peptide: physiology and pathophysiology. Physiol Rev. 2014;94:1099-142.

11. Kim J, Padanilam BJ. Renal nerves drive interstitial fibrogenesis in obstructive nephropathy. J Am Soc Nephrol. 2013; 24:229-42.

12. Yoon SP, Kim J. Exogenous CGRP upregulates profibrogenic growth factors through PKC/JNK signaling pathway in kidney proximal tubular cells. Cell Biol Toxicol. 2018;34:25162.

13. Quinlan MR, Docherty NG, Watson RW, Fitzpatrick JM. Exploring mechanisms involved in renal tubular sensing of mechanical stretch following ureteric obstruction. Am J Physiol Renal Physiol. 2008;295:F1-F11.

14. Choksi T, Hay DL, Legon S, Poyner DR, Hagner S, Bloom SR, et al. Comparison of the expression of calcitonin receptor-like receptor (CRLR) and receptor activity modifying proteins (RAMPs) with CGRP and adrenomedullin binding in cell lines. Br J Pharmacol. 2002;136:784-92.

15. Hay DL, Walker CS. CGRP and its receptors. Headache. 2017;57:625-36.

16. Nagae T, Mukoyama M, Sugawara A, Mori K, Yahata K, Kasahara M, et al. Rat receptor-activity-modifying proteins (RAMPs) for adrenomedullin/CGRP receptor: cloning and 
upregulation in obstructive nephropathy. Biochem Biophys Res Commun. 2000;270:89-93.

17. Wang W, Jia L, Wang T, Sun W, Wu S, Wang X. Endogenous calcitonin gene-related peptide protects human alveolar epithelial cells through protein kinase Cepsilon and heat shock protein. J Biol Chem. 2005;280:20325-30.

18. Zhou Y, Zhang M, Sun GY, Liu YP, Ran WZ, Peng L, et al. Calcitonin gene-related peptide promotes the wound healing of human bronchial epithelial cells via PKC and MAPK pathways. Regul Pept. 2013;184:22-9.

19. Long J, Liu M, Liu S, Tang F, Tan W, Xiao T, et al. H2S attenuates the myocardial fibrosis in diabetic rats through modulating PKC-ERK1/2MAPK signaling pathway. Technol Health Care. 2019;27:307-16.

20. Chichger H, Vang A, O'Connell KA, Zhang P, Mende U, Harrington EO, et al. PKC delta and betaII regulate angiotensin II-mediated fibrosis through p38: a mechanism of RV fibrosis in pulmonary hypertension. Am J Physiol Lung Cell Mol Physiol. 2015;308:L827-36.

21. Sui G, Cheng G, Yuan J, Hou X, Kong X, Niu H. Interleukin (IL)-13, Prostaglandin E2 (PGE2), and Prostacyclin 2 (PGI2) Activate Hepatic Stellate Cells via Protein kinase C (PKC) Pathway in Hepatic Fibrosis. Med Sci Monit. 2018;24:213441.

22. Park S, Yoon SP, Kim J. Cisplatin induces primary necrosis through poly (ADP-ribose) polymerase 1 activation in kidney proximal tubular cells. Anat Cell Biol. 2015;48:66-74.

23. Moon D, Yoon S-P, Jang H-S, Noh MR, Ha L, Padanilam BJ, et al. Extraneural CGRP Induces Oxidative Stress in Kidney Proximal Tubule Epithelial Cells. Anat Biol Anthropol. 2019;32:121.

24. Kim J, Padanilam BJ. Renal denervation prevents long-term sequelae of ischemic renal injury. Kidney Int. 2015;87:3508.

25. Lee JS, Lim JY, Kim J. Mechanical stretch induces angiotensinogen expression through PARP1 activation in kidney proximal tubular cells. In Vitro Cell Dev Biol Anim. 2015;51:72-8.

26. Yoon SP, Kim J. Poly (ADP-ribose) polymerase 1 contributes to oxidative stress through downregulation of sirtuin 3 during cisplatin nephrotoxicity. Anat Cell Biol. 2016;49:165-76.

27. Kim J. Spermidine rescues proximal tubular cells from oxidative stress and necrosis after ischemic acute kidney injury. Arch Pharm Res. 2017;40:1197-208.

28. Yoon SP, Kim J. Poly (ADP-ribose) polymerase 1 activation links ischemic acute kidney injury to interstitial fibrosis. J
Physiol Sci. 2015;65:105-11.

29. Kim MJ, Moon D, Jung S, Lee J, Kim J. Cisplatin nephrotoxicity is induced via poly (ADP-ribose) polymerase activation in adult zebrafish and mice. Am J Physiol Regul Integr Comp Physiol. 2020;318:R843-R54.

30. Moon D, Kim J. Cyclosporin A aggravates hydrogen peroxide-induced cell death in kidney proximal tubule epithelial cells. Anat Cell Biol. 2019;52:312-23.

31. Moon D, Park S, Kim S, Kim J, Kim M, Kim K, et al. Altered proinflammatory cytokines and M1 polarization induced by PM2.5 in alveolar macrophages. Appl Ecol Environ Res. 2018;16:7699-712.

32. Kim J, Long KE, Tang K, Padanilam BJ. Poly (ADP-ribose) polymerase 1 activation is required for cisplatin nephrotoxicity. Kidney Int. 2012;82:193-203.

33. Kim J, Yoon SP, Toews ML, Imig JD, Hwang SH, Hammock BD, et al. Pharmacological inhibition of soluble epoxide hydrolase prevents renal interstitial fibrogenesis in obstructive nephropathy. Am J Physiol Renal Physiol. 2015;308:F131-9.

34. Riser BL, Cortes P, Heilig C, Grondin J, Ladson-Wofford S, Patterson D, et al. Cyclic stretching force selectively upregulates transforming growth factor-beta isoforms in cultured rat mesangial cells. Am J Pathol. 1996;148:1915-23.

35. Skutek M, van Griensven M, Zeichen J, Brauer N, Bosch U. Cyclic mechanical stretching modulates secretion pattern of growth factors in human tendon fibroblasts. Eur J Appl Physiol. 2001;86:48-52.

36. Homma T, Akai Y, Burns KD, Harris RC. Activation of S6 kinase by repeated cycles of stretching and relaxation in rat glomerular mesangial cells. Evidence for involvement of protein kinase C. J Biol Chem. 1992;267:23129-35.

37. Vaughan ED, Jr., Sorenson EJ, Gillenwater JY. The renal hemodynamic response to chronic unilateral complete ureteral occlusion. Invest Urol. 1970;8:78-90.

38. Mignini F, Streccioni V, Amenta F. Autonomic innervation of immune organs and neuroimmune modulation. Auton Autacoid Pharmacol. 2003;23:1-25.

39. Wu D, Peng F, Zhang B, Ingram AJ, Kelly DJ, Gilbert RE, et al. PKC-beta1 mediates glucose-induced Akt activation and TGF-beta1 upregulation in mesangial cells. J Am Soc Nephrol. 2009;20:554-66.

40. Ohshiro Y, Ma RC, Yasuda Y, Hiraoka-Yamamoto J, Clermont $\mathrm{AC}$, Isshiki $\mathrm{K}$, et al. Reduction of diabetes-induced oxidative stress, fibrotic cytokine expression, and renal dysfunction in protein kinase Cbeta-null mice. Diabetes. 2006;55:3112-20. 